Research Article

\title{
Prediction of Pore Size Characteristics of Needle-Punched Nonwoven Geotextiles Subjected to Uniaxial Tensile Strains
}

\author{
Lin Tang, ${ }^{1}$ Qiang Tang $\mathbb{D}^{2}{ }^{2}$ Aolai Zhong, ${ }^{1}$ and Hanjie $\mathbf{L i}^{1}$ \\ ${ }^{1}$ Department of Civil Engineering, Harbin Institute of Technology at Weihai, Weihai 264209, China \\ ${ }^{2}$ School of Rail Transportation, Soochow University, Suzhou 215000, China \\ Correspondence should be addressed to Qiang Tang; tangqiang@suda.edu.cn
}

Received 15 March 2020; Revised 17 May 2020; Accepted 26 May 2020; Published 23 June 2020

Academic Editor: Guoqing Cai

Copyright (c) 2020 Lin Tang et al. This is an open access article distributed under the Creative Commons Attribution License, which permits unrestricted use, distribution, and reproduction in any medium, provided the original work is properly cited.

A modified theoretical model has been proposed to predict the pore size characteristics of nonwoven geotextiles under certain uniaxial tensile strains, considering the difference between the out-of-plane Poisson's ratio and the in-plane Poisson's ratio of geotextiles. The pore size distributions (PSDs) and $\mathrm{O}_{95}$ subjected to different levels of uniaxial tensile strains in two needlepunched nonwoven geotextiles have been investigated by the dry sieving test. The variation of the fibre orientation with tensile strains and the corresponding effect on pore sizes has been evaluated by image analysis. The out-of-plane Poisson's ratio and the in-plane Poisson's ratio of geotextiles have been examined. A comparison has been made between the predictions of the original and the modified models. It is shown that the modified model can more accurately predict the decreasing rate of the PSDs, $\mathrm{O}_{95}$, and $\mathrm{O}_{98}$ than the original one. The corrected theoretical $\mathrm{O}_{95}$ and $\mathrm{O}_{98}$ under certain strains can provide a reference for the filtration design under engineering strains. The fibres reorientating to the loading direction result in the increase of the directional parameter with increasing tensile strains, which leads to the decrease of pore sizes. The theoretical PSDs are sensitive to the variation of directional parameter.

\section{Introduction}

Nonwoven geotextiles are widely used as filtration and drainage materials in various fields [1]. To ensure the retention of the soil without influencing the flow of seepage water, the design of geotextiles needs to meet several criteria, including retention, permeability, and anticlogging capabilities, which are often based on the relationship between the characteristic pore sizes $\mathrm{O}_{95}$ or $\mathrm{O}_{98}$ and soil grain sizes [1-7]. The filtration applications of geotextiles are typically subjected to tensile strains and result in noticeable variations of pore size and permeability in nonwoven geotextiles [8-14]. However, unstrained pore sizes are commonly tested and used in design, which induces the failure in the engineering application [8-14]. Therefore, accurate determination of pore sizes at certain tensile strains is essential in the filtration design of nonwoven geotextiles.

There is still limited theoretical model to predict the effect of uniaxial tensile strain on the pore sizes in geotextiles
$[13,14]$. Based on the Poisson Polyhedron Theory, which can predict a radius distribution of circles inscribed in the polygons, a series of theoretical models of pore size distributions (PSDs) of unstrained nonwoven structures and nonwoven geotextiles have been established [15-20]. The models have also been extended for uniaxial and biaxial tensile strain conditions [13, 21]. Silva et al. [22] have developed image-based technique for measuring pore size distributions of nonwoven geotextiles depending on the theory. Furthermore, a three-dimensional structure of absorptive glass mat separator has been established based on the theory [23]. Many kinds of porous media have been employed in the experiments to prove the validity of these models, including nonwoven heat-bonded geotextiles, hybrid needle punched nonwoven geotextiles, spunbonded nonwoven geotextiles, thermally bonded nonwoven structures, and glass mat $[12,13,15-23]$. The fibre orientation distribution is an important parameter in the model, which needs to be estimated by image analysis [17-20]. Due to the 
fact that the microscopes can typically focus on limited layers of the fibres, the samples employed in the literature were relatively thin, which were generally less than $250 \mathrm{~g} / \mathrm{m}^{2}$ [13-23]. If the sample is relatively thick, the fibres in deep layers will be blurry and cannot be evaluated with an optical microscope.

In the theoretical models of PSDs, a nonwoven structure or geotextile is assumed to be an isotropic material [13-21], which means the in-plane and out-of-plane Poisson's ratios are taken as the same value. Also, the directional parameter $K_{\alpha}$ at different levels of uniaxial tensile strains was not given in the literature [13-21]. The strained $K_{\alpha}$ was calculated from an equation instead of the statistical work of reorientated fibres [13, 17]. And limited experiments of nonwoven geotextiles have been carried out in validating or improving the theoretical model.

When it comes to the experiments about the influence of the uniaxial tensile strain on the pore sizes or permeability of nonwoven geotextiles, the results are still scant [8-14]. Fourie and Kuchena [8] demonstrated that tensile strain can lead to dramatic decreases in the flow rate through soilgeotextile systems for needle-punched nonwoven geotextiles. Edwards and Hsuan [11] reported that the needlepunched geotextile shows a decrease in flow rate, whereas the heat-set nonwoven geotextile experiences an increase, when subjecting to uniaxial tensile loads. The PSDs of three needle-punched geotextiles tested by $\mathrm{Wu}$ and Hong [24] decrease with uniaxial tensile strains in wet sieving tests. And the results of $\mathrm{Wu}$ et al. [10] illustrated the pore size and the mean flow rate through two heat-bonded nonwoven geotextiles increase with the increase in uniaxial tensile strain. It seems that the uniaxial strain results in the decrease of pore sizes for the needle-punched geotextiles, and the opposite trend was observed for heat-bonded nonwoven geotextiles. More experiments still need to be done to verify the conclusions [8-14, 24].

Therefore, in this study, an existing model of PSDs subjected to uniaxial tensile strains has been modified, considering the difference between the in-plane and out-ofplane Poisson's ratios of geotextiles. Two needle-punched nonwoven geotextiles were employed in dry sieving tests (ASTM D4751-16(A)) [4] to estimate the PSDs under uniaxial tensile strains. The directional parameters $K_{\alpha}$ at different levels of uniaxial tensile strains have been obtained from the image analysis of the fibres reorientation. Also, the in-plane and out-of-plane Poisson's ratios of geotextiles have been estimated. Comparisons have been made between the predictions of the modified model and the original model with the experimental results. The modified model can more accurately predict the decreasing tendency of PSDs, and the corrected $\mathrm{O}_{95}$ and $\mathrm{O}_{98}$ under certain strain can be used as a reference in design.

\section{Theoretical Model}

2.1. Original Model. Depending on an unstrained pore model of Rawal et al. [12, 13, 17-20], a theoretical model of the PSDs subjected to uniaxial tensile strains is shown as follows. The cumulative probability $F_{f}(d)$ of a particle with diameter $d$ passing through the layers of nonwoven is shown in the following equations [13, 17-20]:

$$
F_{f}(d)=1-\left[\left(1+\omega d+\frac{\omega^{2} d^{2}}{2}\right) e^{-\omega d}\right]^{N},
$$

where

$$
\begin{aligned}
\omega & =\frac{4 V_{f}(\varepsilon) K_{\alpha}\left(\beta_{f}\right)}{\pi D_{f}}, \\
N & =\frac{T_{g}}{D_{f}}, \\
V_{f}(\varepsilon) & =\frac{V_{f}}{(1+\varepsilon)(1-\nu \varepsilon)^{2}}, \\
K_{\alpha}\left(\beta_{f}\right) & =\int_{-(\pi / 2)-\alpha}^{(\pi / 2)-\alpha}\left|\cos \beta_{f}\right| \chi\left(\beta_{f}\right) \mathrm{d} \beta_{f}, \\
V_{f} & =\frac{\mu}{T_{g} \rho_{h}},
\end{aligned}
$$

where $\omega$ is the coverage parameter; $N$ is the number of layers; $V_{f}$ is the total fibre volume fraction; $\varepsilon$ is the uniaxial tensile strain; $K_{\alpha}$ is the directional parameter; $\chi\left(\beta_{f}\right)$ is the orientation distribution function of fibres; and $\beta_{f}$ is the orientation angle of fibres subjected to strains. $D_{f}$ is the fibre diameter; $\nu$ is Poisson's ratio of the nonwoven. $\mu$ is the initial mass per unit area; $T_{g}$ is the nonwoven thickness; $\rho_{h}$ is the fibre density. The details of the parameters were explained in the literature $[12,13,17-20]$.

2.2. Modified Model. In equation (4), the uniaxial tensile behaviour of a nonwoven geotextile is taken as a plane stress problem. And the out-of-plane Poisson's ratio and the inplane Poisson's ratio are taken as the same parameter $\nu$.

According to the experimental results in the previous literature and this study, the out-of-plane Poisson's ratio of nonwoven geotextiles seems to be smaller than the in-plane Poisson's ratio [13, 18, 24-27]. Rawal and Agrahari [13] demonstrated that the in-plane Poisson's ratios in machine direction range between 2.38 and 3.81 for two thermally bonded nonwovens. The relationship of in-plane Poisson's ratio and longitudinal strain was determined by Rawal et al. [18], and the in-plane Poisson's ratio can increase from 2.1 to 4.0 with increasing strains. The in-plane Poisson's ratio of a nonwoven geotextile tested by Shukla et al. [25] remains 1.75 from zero to $10 \%$ strain. Kutay et al. [26] reported that the lateral strain is always greater than the axial strain for a needle-punched nonwoven geotextile, and Poisson's ratio at failure is equal to 2.1. In the literature, the in-plane Poisson's ratios are at least equal to or larger than 1.0.

When it comes to the out-of-plane Poisson's ratio, Verma et al. [27] tested the out-of-plane Poisson's ratio of two needle-punched polypropylene nonwoven NW1 and NW2. Both of the out-of-plane Poisson's ratios of the two geotextiles range between 0.21 and 0.37 , when the strains 
increase from 0 to $10 \%$. Also, the decrease of thickness of three nonwoven geotextiles (referred to as GT1, GT2, and GT3) with increasing uniaxial strain was tested by Wu and Hong [24], as shown in Figure 1. The decrease of the thickness with tensile strains is approximately linear. Hence, in this study, the experimental data are linearly fitted, and the slopes of the fitted lines $k$ are used to calculate the out-ofplane Poisson's ratio $\nu_{\perp}$, shown as follows:

$$
\nu_{\perp}=\frac{-\varepsilon_{t}}{\varepsilon}=\frac{k}{t_{0}},
$$

where $\varepsilon_{t}$ is the strain in the thickness and $\varepsilon$ is the in-plane uniaxial tensile strain. $t_{0}$ is the unstrained thickness of a geotextile. And the $v_{\perp}$ for GT1, GT2, and GT3 are calculated to be $0.17,0.36$, and 0.14 , respectively, as shown in Figure 1, which are smaller than the in-plane Poisson's ratio in the literatures [13, 18, 25, 26].

In this study, equation (4) is modified to the following equation:

$$
V_{f}(\varepsilon)=\frac{V_{f}}{(1+\varepsilon)\left(1-\nu_{\perp} \varepsilon\right)\left(1-v_{/ /} \varepsilon\right)},
$$

where $v_{/ /}$is the in-plane Poisson's ratio, which should be determined depending on the direction of the uniaxial tensile strain $\varepsilon$. And the total fibre volume fraction is influenced by the in-plane lateral strain as well as the strain in the thickness of geotextiles.

Thus, the modified model of PSDs subjected to uniaxial tensile strains combines equations (1)-(3), (5), (6), and (8).

In the filtration criteria of geotextiles, $\mathrm{O}_{95}$ is a commonly used characteristic pore size; it indicates that $95 \%$ of the pores are smaller than that size $[1,4]$, whereas the theoretical $\mathrm{O}_{95}$ read from the theoretical PSD cannot fit perfectly with the value of experimental $\mathrm{O}_{95}$ in the literatures $[13,17-20]$. If a strained theoretical $\mathrm{O}_{95}$ needs to be used in the filtration design under a certain engineering strain, the difference between the theoretical and experimental $\mathrm{O}_{95}$ should be corrected. The experimental $\mathrm{O}_{95}$ of an unstrained geotextile can be easily tested before applications or be given by the manufactures. Hence, the difference between the unstrained experimental and theoretical $\mathrm{O}_{95}$ can be used to correct the error of the strained theoretical $\mathrm{O}_{95}$, as long as the decreasing rate can be accurately predicted. Then when the uniaxial tensile strain is $\varepsilon$, the strained $\mathrm{O}_{95}$ used in design can be calculated as follows:

$$
\mathrm{O}_{95 \text { corrected }}(\varepsilon)=\mathrm{O}_{95 \exp }(0)-\mathrm{O}_{95 \text { theo }}(0)+\mathrm{O}_{95 \text { theo }}(\varepsilon) \text {, }
$$

where $\mathrm{O}_{95 \text { corrected }}(\varepsilon)$ is the corrected theoretical $\mathrm{O}_{95}$ under the strain $\varepsilon$, which may be used in the filtration design criteria, $\mathrm{O}_{95 \exp }(0)$ is the experimental $\mathrm{O}_{95}$ of unstrained geotextile samples, $\mathrm{O}_{95 \text { theo }}(0)$ is the $\mathrm{O}_{95}$ read from the theoretical PSD under the strain $0 \%$, and $\mathrm{O}_{95 \text { theo }}(\varepsilon)$ is the $\mathrm{O}_{95}$ read from the theoretical PSD under the strain $\varepsilon$.

\section{Experimental Procedure}

3.1. Materials Used. To verify the rationality of the modified model, dry sieving test was adopted to test the changes in the

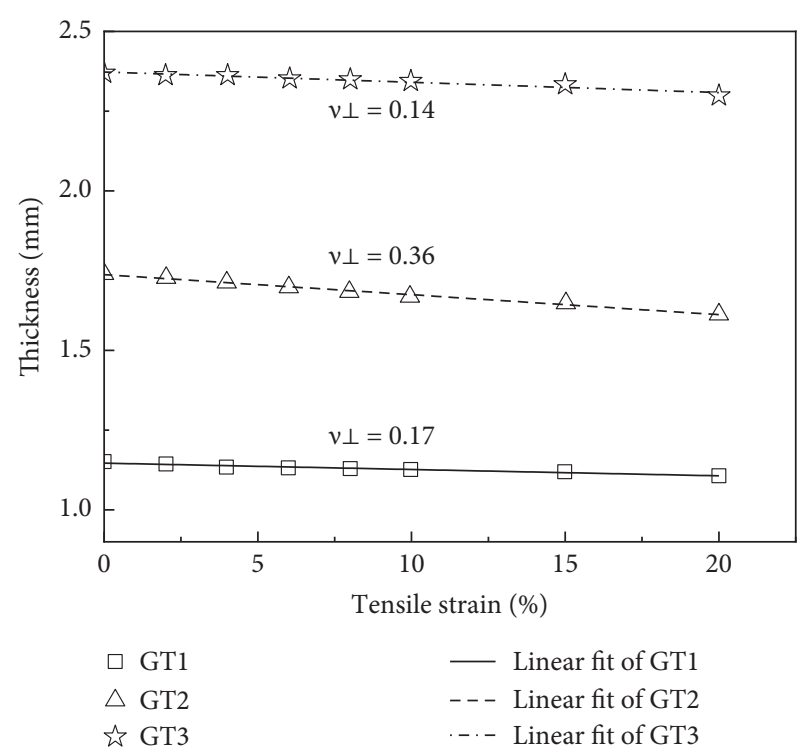

Figure 1: Variations in geotextile thickness with tensile strains (data sourced from reference [24]).

PSDs of two needle-punched nonwoven geotextiles under uniaxial tensile strains. Due to the fact that the fibre orientation needs to be estimated by image analysis, relatively thin samples were employed. The geotextiles were designated as NW100 and NW200, which indicated that the masses per unit area of the two geotextiles were approximately $107 \mathrm{~g} / \mathrm{m}^{2}$ and $225 \mathrm{~g} / \mathrm{m}^{2}$. Details of the geotextiles used are described in Table 1.

3.2. Apparatus and Procedure. Rowe and Mylleville [28] demonstrated that the strain imposed on geotextiles in the direction perpendicular to the long axis of the embankment can be as much as $10 \%$. Izadi et al. [29] noted that the strains in a geotextile due to impact loadings were in the range of $3.5-5 \%$. Won and Kim [30] mentioned that there is a $6 \%$ strain in a geotextile of a $5 \mathrm{~m}$ high soil wall, and Schimelfenyg et al. [31] found a larger than $7 \%$ strain for a geotextile in warp and fill directions of a containment dyke. Fourie and Addis [9] concluded that most of the decrease of filtration opening size has already occurred under the application of the smallest load. According to the fact that the strain levels recorded in the literatures are smaller than $10 \%$, the uniaxial tensile strains of $3 \%, 5 \%$, and $10 \%$ were selected to study the influence of strains on pore sizes. The test procedures were as follows:

(1) A universal tensile test apparatus was used to form strained geotextile specimens for the dry sieving test. The tensile loads were applied along the machine direction during testing. When a geotextile specimen was stretched to a designated strain, the specimen was secured by clamps, as shown in Figure 2(a). The internal diameters of the clamps are $200 \mathrm{~mm}$, which can be fitted on the $200 \mathrm{~mm}$ diameter sieves. The size of an unstrained specimen used for dry sieving test is illustrated in Figure 2(b). Then, the clamped 
TABle 1: Properties of nonwoven geotextiles and structures.

\begin{tabular}{lcc}
\hline & NW100 & NW200 \\
\hline Mass per unit area $\left(\mathrm{g} / \mathrm{m}^{2}\right)$ & 107 & 225 \\
Thickness $(\mu \mathrm{m})$ & 863 & 1690 \\
Density of fibre $\left(\mathrm{g} / \mathrm{cm}^{3}\right)$ & 1.32 & 1.32 \\
Diameter $(\mu \mathrm{m})$ & 23 & 23 \\
Out-of-plane Poisson's ratio & 0.17 & 0.31 \\
In-plane Poisson's ratio (machine direction) & 1.17 & 1.16 \\
\hline
\end{tabular}

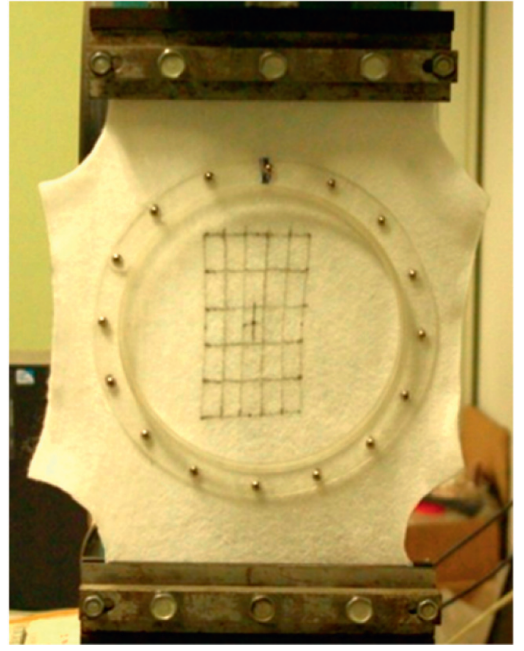

(a)

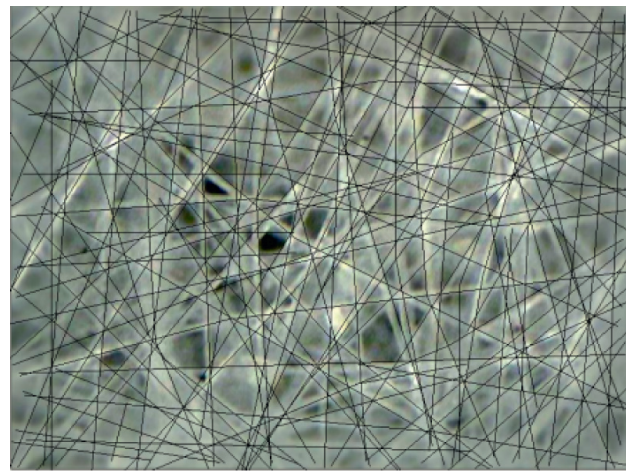

(c)

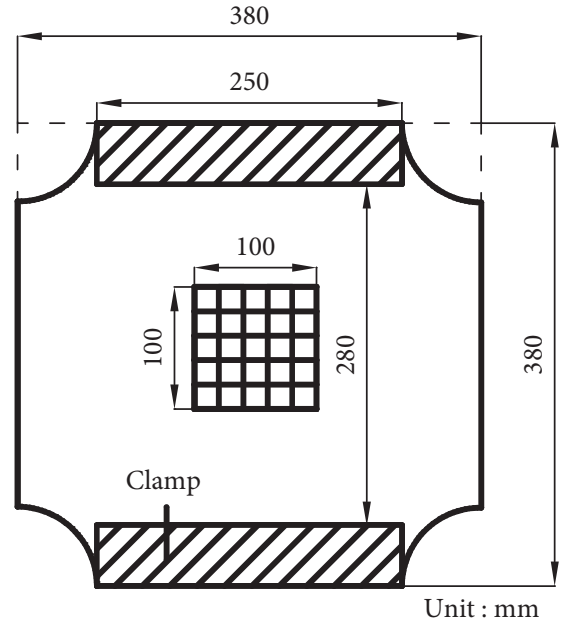

(b)

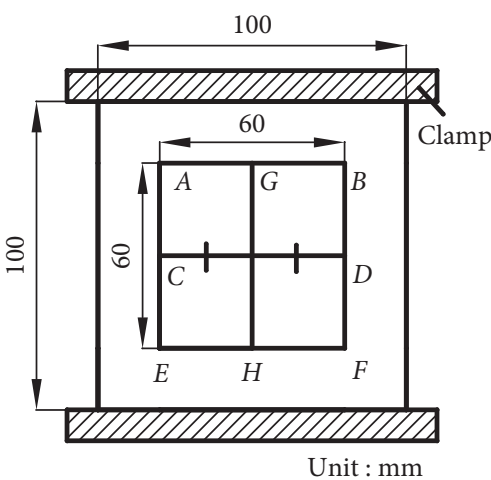

(d)

Figure 2: Preparation of strained geotextile specimen. (a) Photograph of strained geotextile specimen secured by clamps. (b) Schematic of an unstrained specimen for the dry sieving test. (c) Measurement of fibre orientations. (d) Schematic of unstrained specimen for the in-plane Poisson's ratio test.

geotextile specimens were cut free from the apparatus. Grids were drawn on the specimens before testing as an indicator for the tensile strain and the strain reversal after cutting.

(2) The microscopic image of the clamped specimen was taken by a microscope. The fibres were recognized manually by drawing straight lines on the fibres using AutoCAD ${ }^{@}$, as presented in Figure 2(c). And the statistical work was done by calculate the proportion of lines for $10^{\circ}$ orientation angle interval with respect to the machine direction $0^{\circ}[12,13,17-20]$. And then, the directional parameter $K_{\alpha}$ was calculated by equation (5). More than 120 fibres were involved in the statistical work of each image.

(3) The thickness of the clamped geotextile specimen was tested under $2 \mathrm{kPa}$ normal pressure by thickness testing instrument (ASTM D5199-12) [32], which is used to calculate the out-of-plane Poisson's ratio. The standard deviations of the thickness of samples under a certain strain range from 3 to $23 \mu \mathrm{m}$. The variations of geotextile thickness with tensile strains are illustrated in Figure 3. And equation (7) is used to give the out-of-plane Poisson's ratios of NW100 and NW200, which are 0.17 and 0.31 , respectively. 


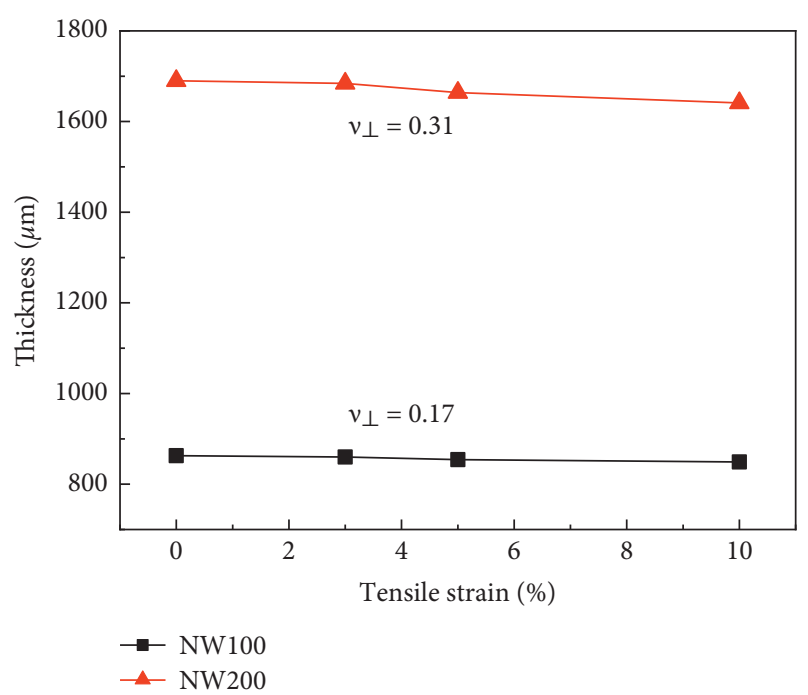

FIgURE 3: Variations in thickness with tensile strains of NW100 and NW200.

(4) Apply commercially available antistatic spray uniformly to the geotextile. And the clamped geotextile was fitted with a pan and a cover and was fixed on a mechanical sieve shaker to conduct dry sieving tests (ASTM D475116(A)) [4]. Spherical glass beads ranging in size from $0.033 \mathrm{~mm}$ to $0.425 \mathrm{~mm}$ were utilized.

(5) The in-plane Poisson's ratio of geotextiles was tested by image analysis in the machine direction. The size of an initial specimen used for in-plane Poisson's ratio test is illustrated in Figure 2(d). The geotextile specimen was clamped to create a $100 \mathrm{~mm} \times 100 \mathrm{~mm}$ square test area. A $60 \mathrm{~mm} \times 60 \mathrm{~mm}$ square was drawn on the specimen. Giroud [33] mentioned that the Poisson's ratio derived from the lateral strain at mid-length of the specimen tends to be overestimated. Hence, the average lateral strain of lines $A B, C D$, and $E F$ of the marked square was used to calculate the in-plane Poisson's ratio as equations (10)-(12). The standard deviations of in-plane Poisson's ratio are 0.003 for NW100 and 0.05 for NW200, respectively:

$\varepsilon_{1}=\frac{\left(\left(A^{\prime} B^{\prime}-A B\right) / A B+(C \prime D \prime-C D) / C D+(E / F \prime-E F) / E F\right)}{3}$,

$\varepsilon_{2}=\frac{G^{\prime} H^{\prime}-G H}{G H}$,

$v_{/ /}=-\frac{\varepsilon_{1}}{\varepsilon_{2}}$,

where $\varepsilon_{1}$ is the average lateral strain and $\varepsilon_{2}$ is the longitudinal extension strain. $A^{\prime} B^{\prime}$ and $A B$ are the strained length and initial length of the line $A B$. The same goes for the other marked lines.

\section{Results}

4.1. Fibre Orientation. The machine direction of the geotextiles was set as $0^{\circ}$ in the statistics, which is also the direction for the loading in the tensile test. Figure 4 illustrates the microstructures of the unstrained and strained (10\%) NW100 specimens. The histograms of the relative frequency of fibres for NW100 and NW200 under designated strains are given in Figure 5. With the strain increasing, the randomly distributed fibres reorientate to the loading direction in Figure 4, which agrees with the histograms of relative frequency of fibres for NW100, as shown in Figure 5. The relative frequency at $0^{\circ}$ increases from 0.14 to 0.24 for NW100 and from 0.08 to 0.16 for NW200, when the strain increases from $0 \%$ to $10 \%$. For NW100, there is an increase trend for the relative frequency of fibres around $0^{\circ}$, especially from $-20^{\circ}$ to $20^{\circ}$. In Figure $5(\mathrm{a})$, the relative frequency of fibres for NW 100 at $0^{\circ}$ is a little bit larger than the others, with the relative frequency of the other directions comparatively uniform. That agrees with the conclusion that most of nonwoven geotextiles are preferentially orientated $[12,13]$. For NW200, the relative frequency of fibres for the unstrained NW200 is comparatively uniform in Figure 5(e). With an increase of strain from $0 \%$ to $10 \%$, the relative frequency of fibres increased from 0.09 to 0.12 for $-10^{\circ}$ angle and from 0.01 to 0.05 for $10^{\circ}$ angle, respectively.

The directional parameter $K_{\alpha}$ is defined as the average distance between the bonds projected on the planar direction [17-20]. The $K_{\alpha}$ at designated tensile strains is calculated from equation (5), which is the integral of the product of $\left|\cos \beta_{f}\right|$ and the corresponding relative frequency of fibres for $\beta_{f}$ from $-90^{\circ}$ to $90^{\circ}$, as given in Table 2 . The $K_{\alpha}$ of both samples increases with uniaxial tensile strains. When the strain increases from $0 \%$ to $10 \%$, the $K_{\alpha}$ increases from 0.63 to 0.76 for NW100 and from 0.63 to 0.72 for NW200.

A parametric study is performed to calculate the pore size distributions for different values of $K_{\alpha}$, as shown in Figure 6 . When the $K_{\alpha}$ increases from 0.6 to 0.8 by $33 \%$ for the two samples under 0\% strain, the PSDs of NW100 and NW200 move towards the direction of small pore sizes. The $\mathrm{O}_{95}$ read from the theoretical PSDs decreases from 319 to $238 \mu \mathrm{m}$ by $34 \%$ for NW 100 and from 223 to $170 \mu \mathrm{m}$ by $31 \%$ for NW200. The larger the $K_{\alpha}$ is, the smaller the theoretical pore sizes will be. The theoretical pore size is sensitive to the variation of $K_{\alpha}$. Hence, the accurate determination of $K_{\alpha}$ is critical to the prediction of pore size under tensile strains. The theoretical results also agree with the phenomenon that the fibres reorientation to one direction results in narrower space between the fibres and the decrease of the pore sizes.

4.2. Pore Size Distribution. The experimental PSDs are plotted by the cumulated frequency of the pore size versus the pore size, as presented in Figure 7. The experimental PSDs of both NW100 and NW200 move towards the direction of small pore sizes with increasing strain, demonstrating the decrease of pores of different sizes. The shapes of the PSD curves for NW100 and NW200 do not vary regularly under different strains. Depending on the physical 


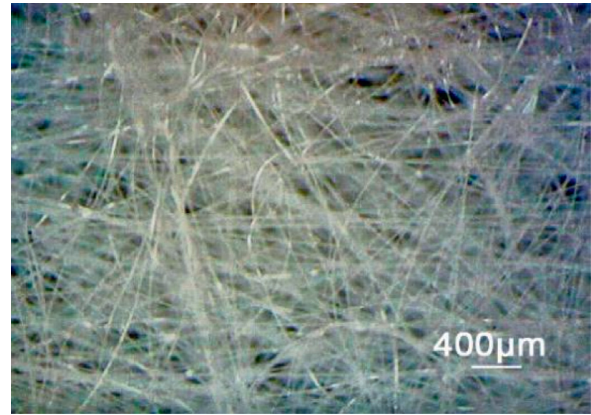

(a)

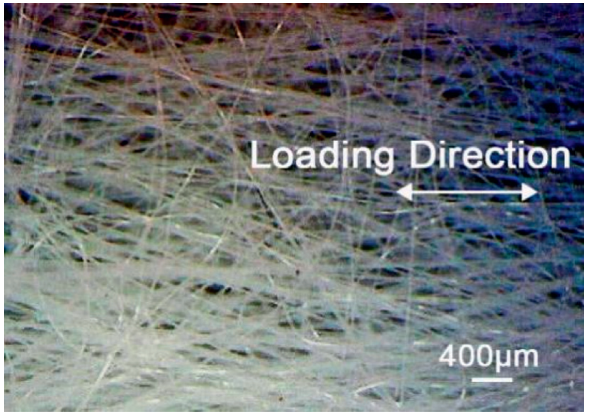

(b)

FIgURE 4: Microstructures of an NW100 geotextile specimen. (a) 0\% strain. (b) 10\% uniaxial tensile strain.

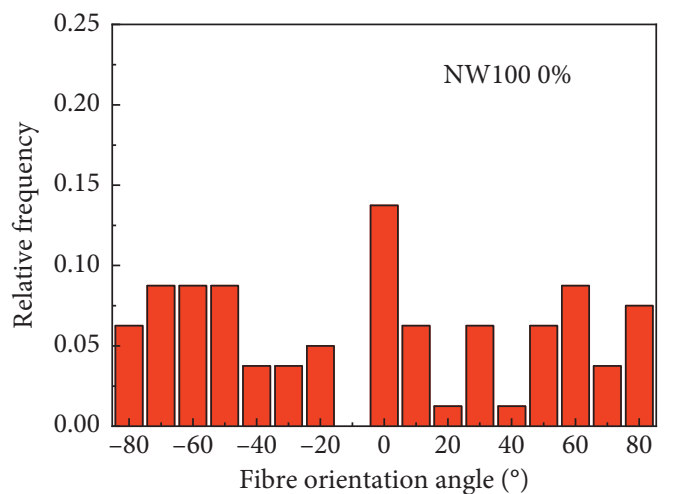

(a)

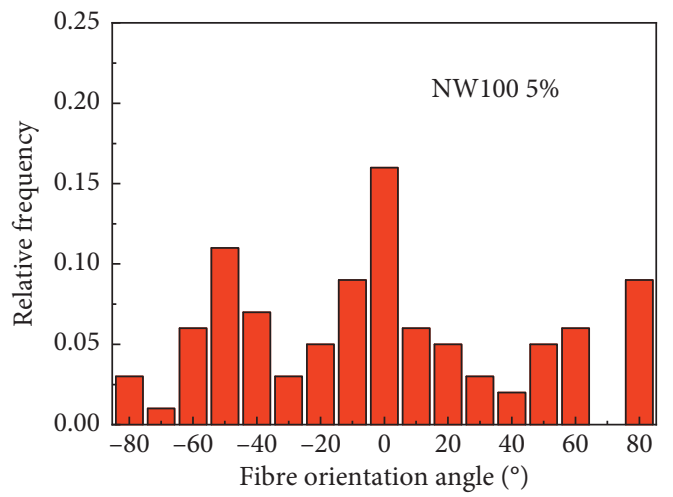

(c)

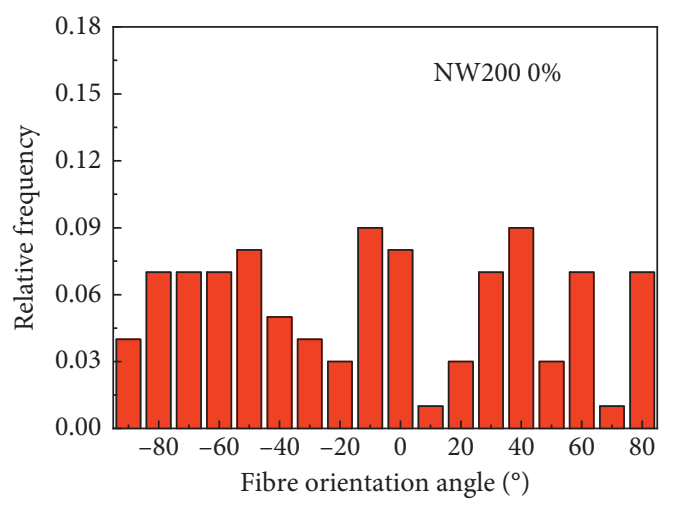

(e)

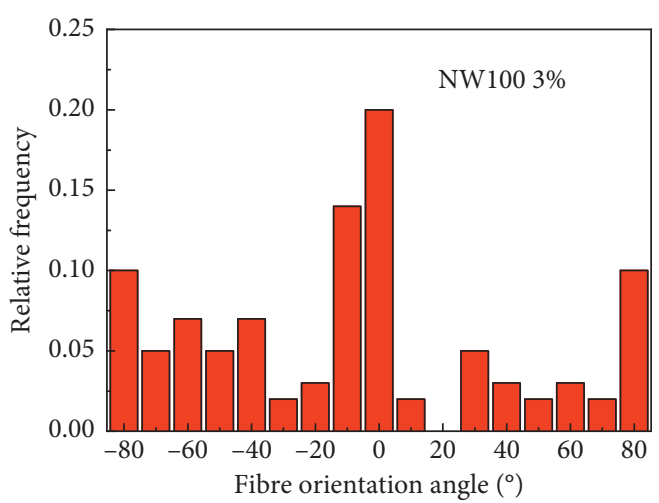

(b)

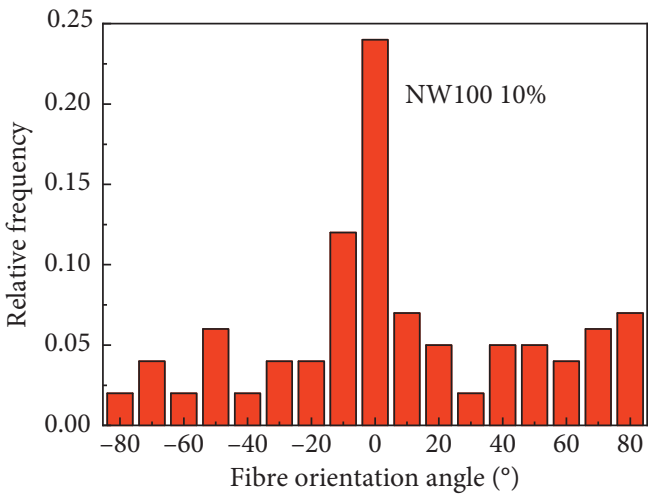

(d)

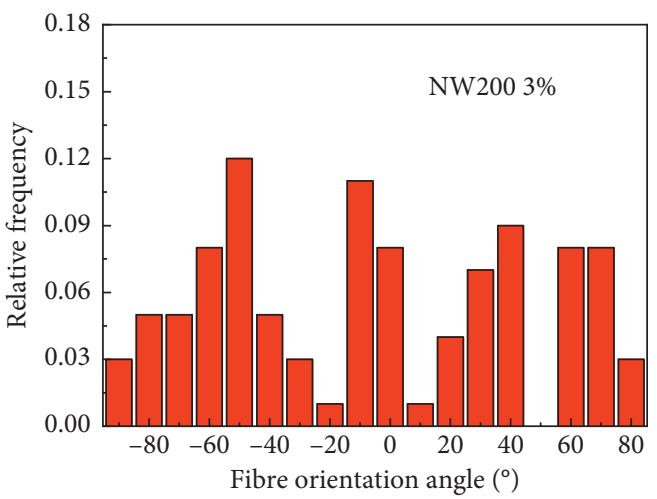

(f)

Figure 5: Continued. 


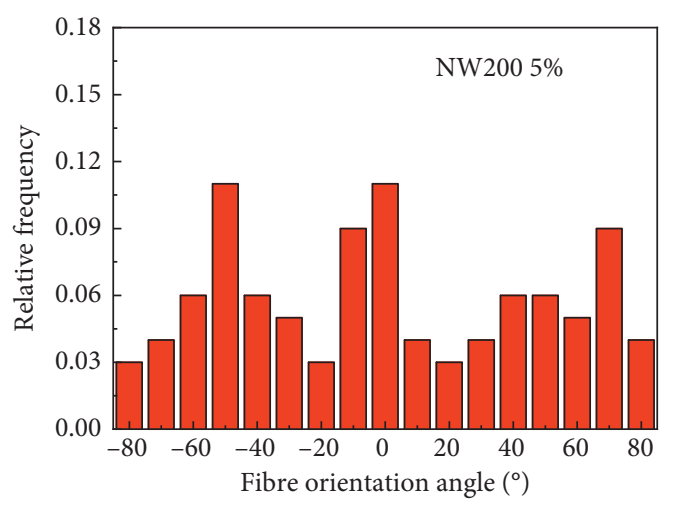

(g)

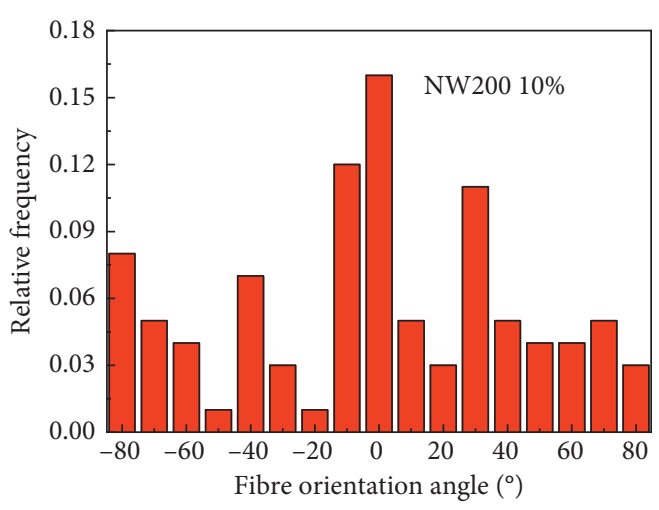

(h)

FIGURE 5: Histograms of relative frequency of fibres subjected to different uniaxial tensile strain. (a) NW100 0\%. (b) NW100 3\%. (c) NW100 5\%. (d) NW100 10\%. (e) NW200 0\%. (f) NW200 3\%. (g) NW200 5\%. (h) NW200 10\%.

TABLE 2: Directional parameter $K_{\alpha}$ at different levels of strains.

\begin{tabular}{lcc}
\hline Strain (\%) & NW100 & NW200 \\
\hline 0 & 0.63 & 0.63 \\
3 & 0.68 & 0.65 \\
5 & 0.71 & 0.69 \\
10 & 0.76 & 0.72 \\
\hline
\end{tabular}

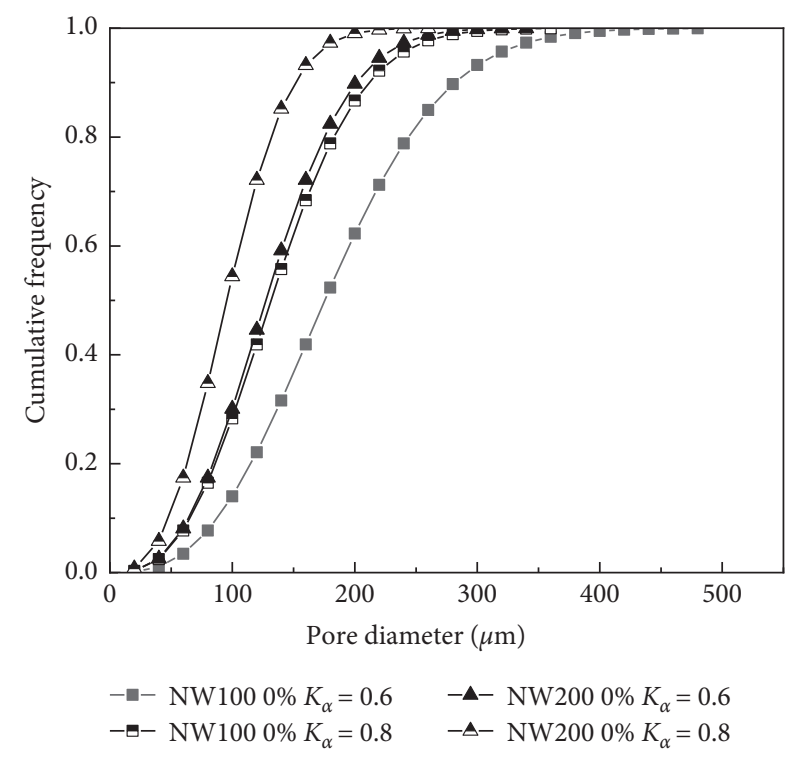

Figure 6: Parametric study of $K_{\alpha}$ at $0 \%$ strain.

properties of the geotextiles, the theoretical PSDs are calculated from the original model $[12,13,18-20]$ and the modified model, labelled as "Theo-O" and "Theo-M," respectively, in Figure 7. Both kinds of the theoretical PSDs decrease with increasing strains. The distances between two adjacent theoretical curves of the modified model are smaller than that of the original one. Evaluating the prediction accuracy of the two models is difficult, because the shapes of PSDs of the two models cannot fit perfectly with the experimental PSDs. Hence, the characteristic pore sizes $\mathrm{O}_{95}$ were determined from the PSDs to quantify the variations.

$\mathrm{O}_{95}$ is not very susceptible to the effect of static electricity in dry sieving tests, which may result in the uptrend of the PSDs in the area of small pores and influence the results of small characteristic pore sizes $[1,4]$. Therefore, the $\mathrm{O}_{95}$ were read from the theoretical and experimental PSDs to compare the predictions of two models. The difference between the theoretical and experimental $\mathrm{O}_{95}$ at $0 \%$ strain was used to calculate the corrected $\mathrm{O}_{95 \text { corrected }}(\varepsilon)$ by using equation (9). The experimental $\mathrm{O}_{95}$ and $\mathrm{O}_{95 \text { corrected }}(\varepsilon)$ are illustrated in Figure 8. The experimental $\mathrm{O}_{95}$ values of $\mathrm{NW} 100$ and NW200 decline with strains. The decreasing tendency of $\mathrm{O}_{95}$ predicted by the modified model agrees better with the experimental $\mathrm{O}_{95}$ than the original model. The original model overestimates the decreasing rate for both NW100 and NW200. It may be attributed to the fact that the original model overestimates the out-of-plane Poisson's ratio.

\section{Discussion}

Rawal and Agrahari [13] validated their model through the image analysis of two thermally bonded nonwoven structures labelled as TB1 and TB2. The physical properties of TB1 and TB2 are tabulated in Table 3. The experimental and theoretical PSDs of the original model are read from the semi-logarithmic figures. When the figure has a linear scale on the $x$-axis, the distances between adjacent theoretical PSDs are obviously larger than those of the experimental results, as illustrated in Figures 9(a) and 9(c). Also, the distances between the strained experimental PSDs and the corresponding theoretical ones cannot be neglected. The $\mathrm{O}_{98}$ values subjected to uniaxial tensile strains were given in the literature. If the theoretical $\mathrm{O}_{98}$ of the original model is corrected by equation (9) and compared with the experimental results, the theoretical $\mathrm{O}_{98}$ drops faster with increasing strains than the experimental result, as shown in Figure 10, which is consistent with the overestimation of the decreasing rate of NW100 and NW200. Furthermore, the 

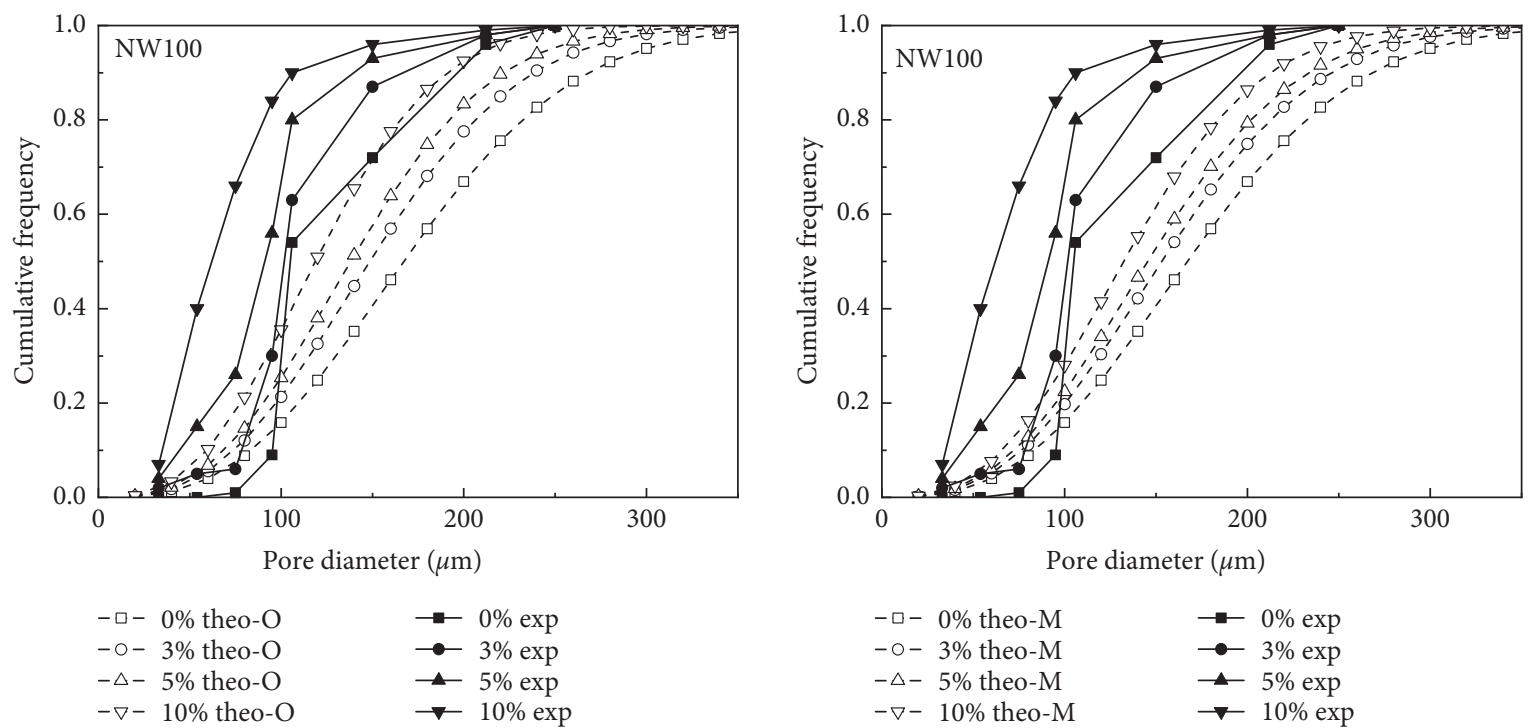

(a)

(b)

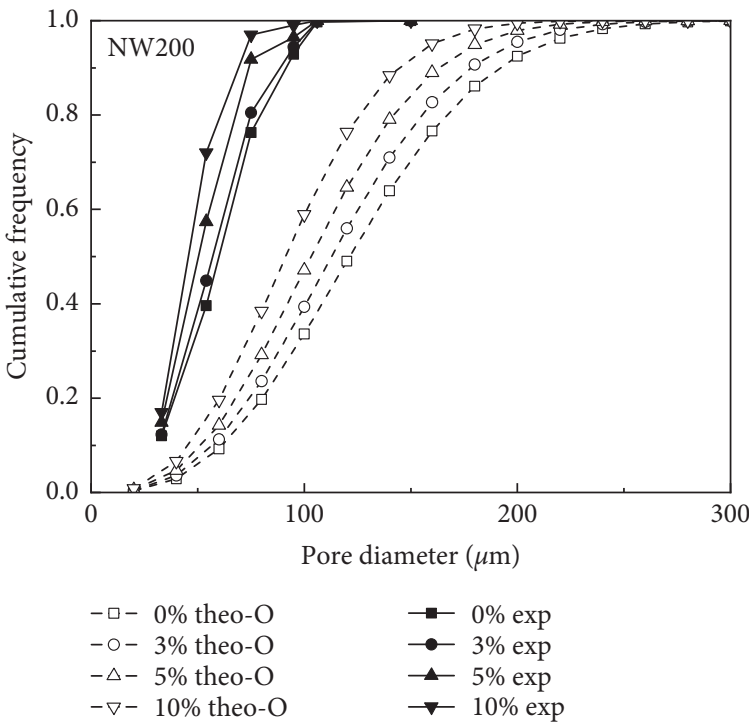

(c)

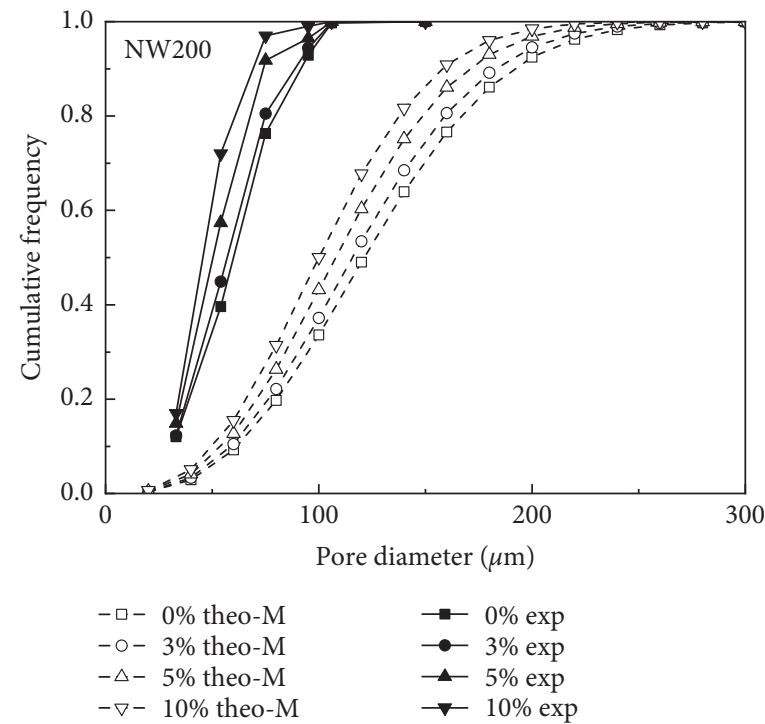

(d)

FIGURE 7: Experimental and theoretical PSDs of dry sieving test. (a) Experimental and theoretical PSDs of the original model for NW100. (b) Experimental and theoretical PSDs of the modified model for NW100. (c) Experimental and theoretical PSDs of the original model for NW200. (d) Experimental and theoretical PSDs of the modified model for NW200.

theoretical PSDs are larger than the experimental ones for NW100, NW200, TB1, and TB2.

The out-of-plane Poisson's ratios of TB1 and TB2 were not considered in the test. The thicknesses of TB1 and TB2 are comparatively small, which are $0.44 \mathrm{~mm}$ and $0.43 \mathrm{~mm}$, respectively. The out-of-plane Poisson's ratios of the thinner specimen in the literature of $\mathrm{Wu}$ and Hong [24] and this study are both 0.17 . If the out-of-plane Poisson's ratios for TB1 and TB2 are assumed to be 0.17, the theoretical PSDs predicted by the modified model are given in Figures 9(b) and $9(\mathrm{~d})$. And the corresponding corrected $\mathrm{O}_{98}$ by using equation (9) are shown in Figure 10. The distances between two adjacent modified theoretical PSDs are more next to that of the experimental results than the original model in
Figure 9. And the modified model can give a better prediction of the decreasing rate of the $\mathrm{O}_{98}$ in Figure 10.

Although the out-of-plane Poisson's ratios for TB1 and TB2 are assumed, the results indicate that the consideration of the out-of-plane Poisson's ratio may lead to more accurate predictions. The prediction of the values of $\mathrm{O}_{95}$ and $\mathrm{O}_{98}$ by the model is not terribly accurate, whereas the decreasing rate predicted by the modified model is acceptable, and the values of $\mathrm{O}_{95}$ and $\mathrm{O}_{98}$ can be corrected depending on the precisely measured unstrained values. Then the $\mathrm{O}_{95}$ under a certain strain can be predicted from the modified model and may be used in the filtration criteria. In this study, only two relatively thin nonwoven geotextiles have been tested to validate the model. Additional experiments on thicker 


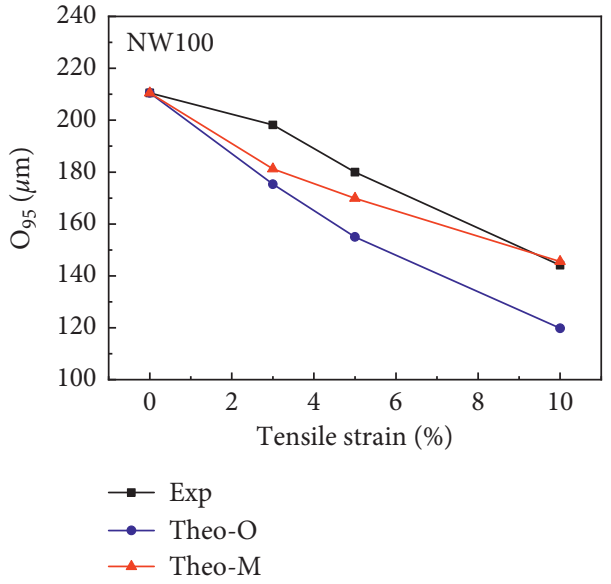

(a)

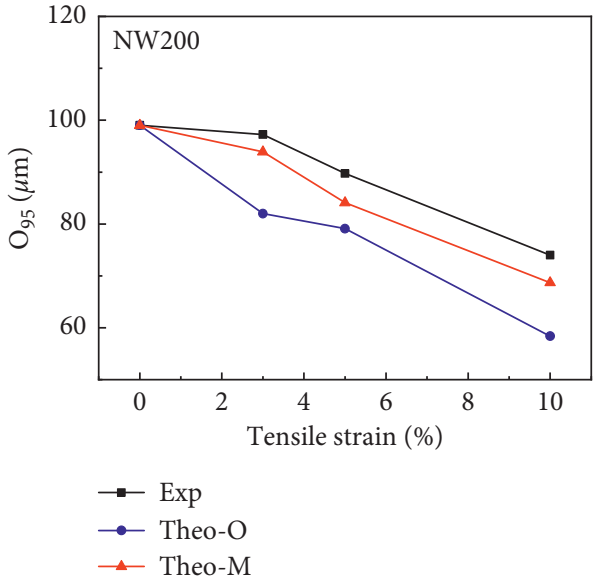

(b)

Figure 8: Experimental and theoretical $\mathrm{O}_{95}$ tested by dry sieving test. (a) NW100. (b) NW200.

TABle 3: Properties of nonwoven structures [13].

\begin{tabular}{lcc}
\hline & TB1 & TB2 \\
\hline Mass per unit area $\left(\mathrm{g} / \mathrm{m}^{2}\right)$ & 30 & 30 \\
Thickness $(\mathrm{mm})$ & 0.44 & 0.43 \\
Density of fibre $\left(\mathrm{g} / \mathrm{cm}^{3}\right)$ & 1.38 & 1.38 \\
Diameter $(\mu \mathrm{m})$ & $16.6^{\mathrm{a}}$ & $28^{\mathrm{a}}$ \\
$K_{\alpha}$ & 0.81 & 0.77 \\
Out-of-plane Poisson's ratio & $0.17^{\mathrm{b}}$ & $0.17^{\mathrm{b}}$ \\
& $2.90(4 \%)$ & $3.81(4 \%)$ \\
In-plane Poisson's ratio in machine direction & $2.64(8 \%)$ & $2.92(8 \%)$ \\
& $2.38(12 \%)$ & $2.61(12 \%)$ \\
\hline
\end{tabular}

Note: ${ }^{\text {T}}$ The diameters of fibres were calculated depending on the parameters given in the literature [13]. TB1 and TB2 were produced by blending the homofil and bicomponent polyester fibres in equal proportions by weight; hence, the diameter of fibres is taken as the average diameter of the two fibres, as mentioned by Rawal and Agrahari [13]. ${ }^{\mathrm{b}}$ Assumed value.

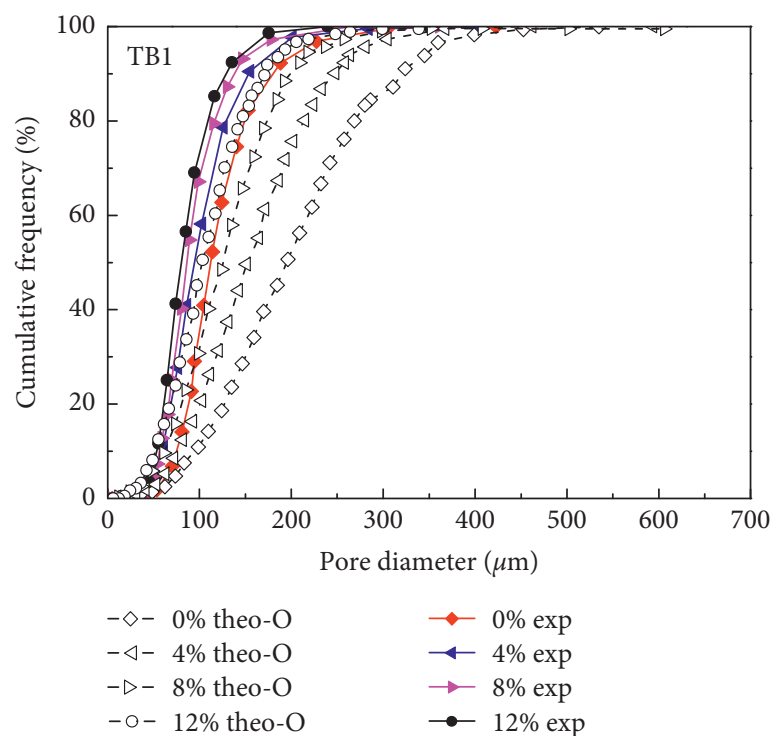

(a)

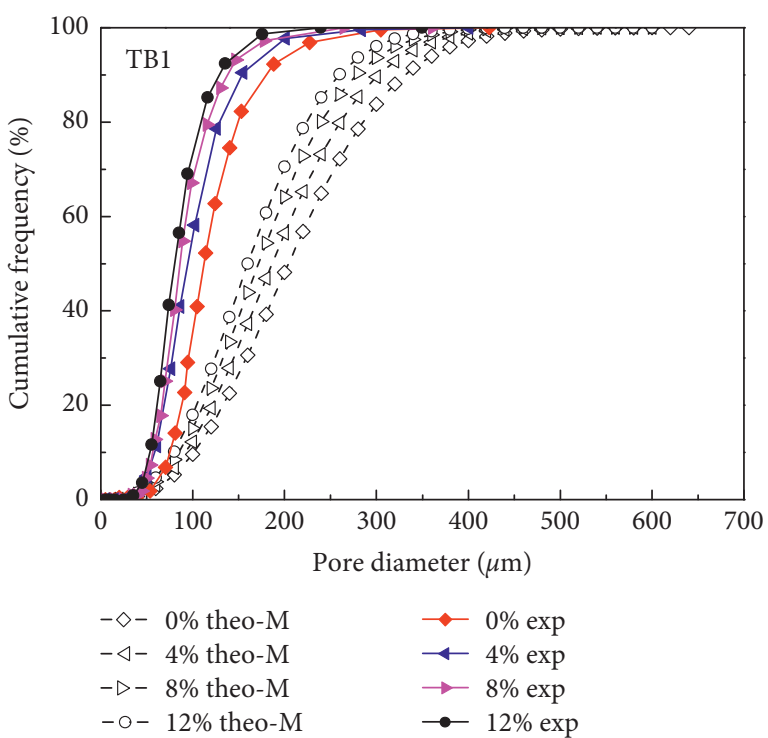

(b)

Figure 9: Continued. 


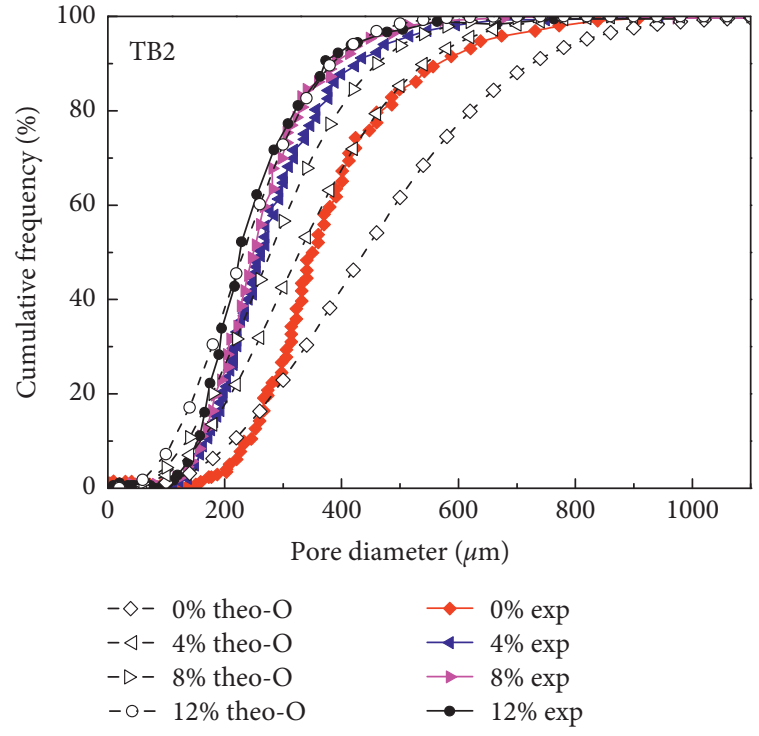

(c)

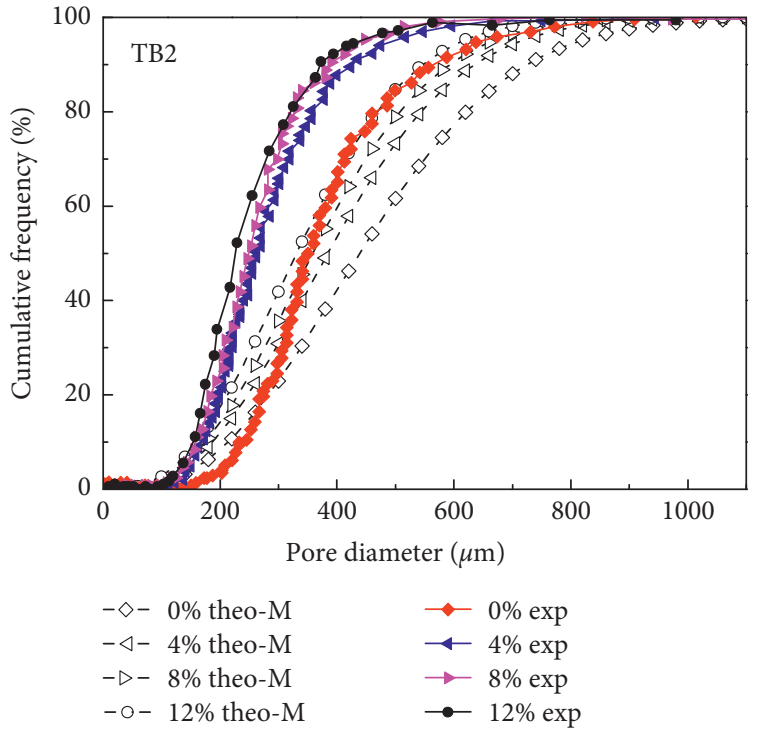

(d)

Figure 9: Experimental and theoretical PSDs of TB1 and TB2. (a) Experimental and theoretical PSDs of the original model for TB1. (b) Experimental and theoretical PSDs of the modified model for TB1. (c) Experimental and theoretical PSDs of the original model for TB2. (d) Experimental and theoretical PSDs of the modified model for TB2 (data of experimental and theoretical PSDs of the original model sourced from reference [13]).

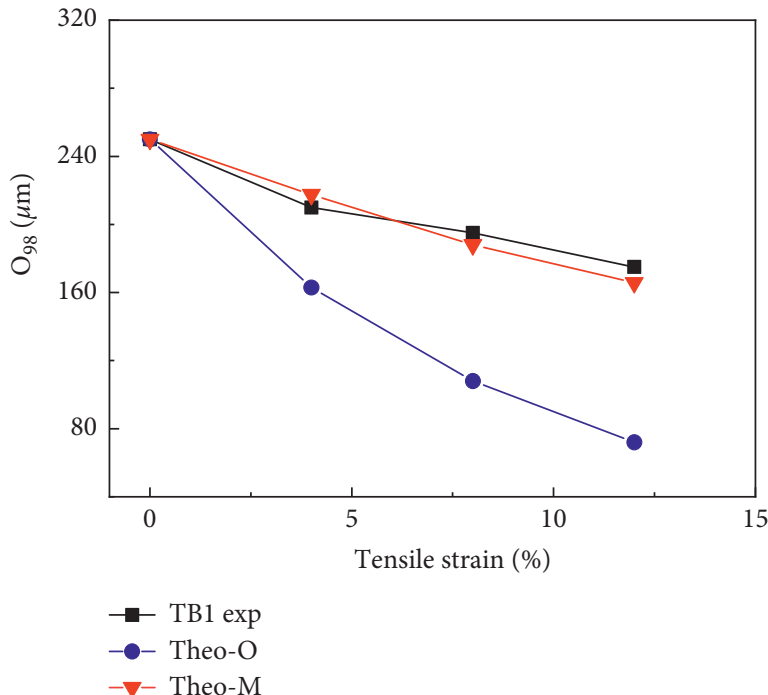

(a)

Figure 10: Experimental and theoretical $\mathrm{O}_{98}$ of image analysis. (a) TB1. (b) TB2 (experimental $\mathrm{O}_{98}$ sourced from reference [13]). nonwoven geotextiles and other test methods of pore size measurement are required to verify the conclusion. Moreover, other loading directions except for the machine direction should be examined.

\section{Conclusions}

In this study, the existing model of pore size distributions of nonwoven geotextiles subjected to uniaxial tensile strains has been modified, considering the effect of the out-

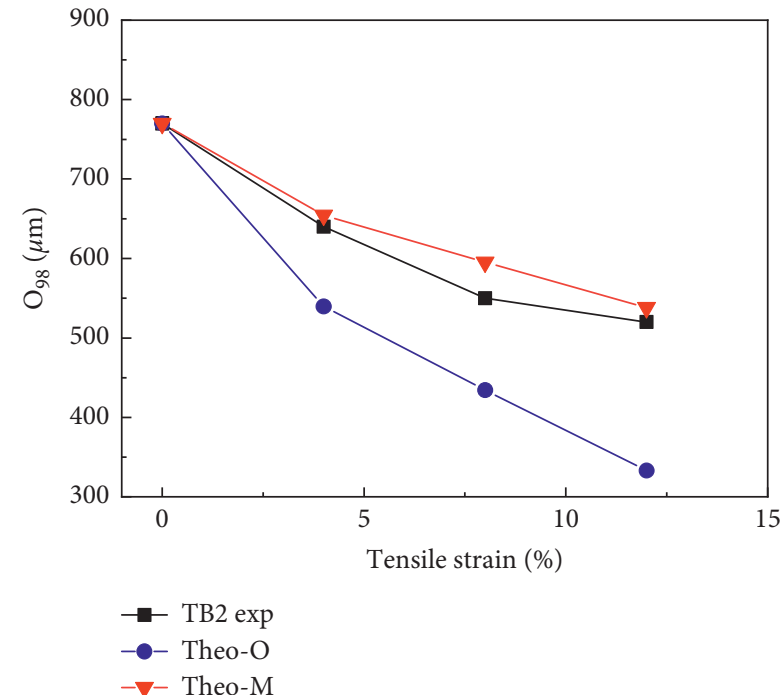

(b)

of-plane Poisson's ratio. The experimental PSDs move towards the direction of small pore sizes with increasing strain, indicating the decrease of pore sizes. The shapes of the experimental PSDs do not vary regularly with strains. The modified model can more accurately predict the decreasing rate of $\mathrm{O}_{95}$ and $\mathrm{O}_{98}$. And the original model may overestimate the decreasing rate and the value of $\mathrm{O}_{95}$ and $\mathrm{O}_{98}$. The corrected $\mathrm{O}_{95}$ predicted by the modified model under a designated strain can provide a reference for the filtration design. 
The randomly distributed fibres reorientate to the loading direction with the increasing uniaxial tensile strain. The relative frequencies of fibres at the loading direction increase from 0.14 to 0.24 for NW100 and from 0.08 to 0.16 for NW200, when the strain increases from $0 \%$ to $10 \%$. Also, there is an increase trend for the relative frequency of fibres around the loading direction. The larger the uniaxial tensile strain is, the larger the $K_{\alpha}$ is, and the smaller the theoretical pore size will be, which agrees with the experimental results. The theoretical PSD is sensitive to the change of $K_{\alpha}$. When the $K_{\alpha}$ increases by $33 \%$, the $\mathrm{O}_{95}$ read from the theoretical PSDs decreases by $34 \%$ for NW100 and by $31 \%$ for NW 200 .

The experimental results indicate that the out-of-plane Poisson's ratio of nonwoven geotextiles is smaller than the in-plane Poisson's ratio. The out-of-plane Poisson's ratio needs to be taken into consideration in the model of geotextiles. Additional experiments are required to verify the conclusions.

\section{Data Availability}

The data used to support the findings of the study are included in the article.

\section{Conflicts of Interest}

The authors declare no conflicts of interest.

\section{Acknowledgments}

This research was funded by the National Natural Science Foundation of China (51708160), Chinese Scholarship Council (CSC No. 201906125022), Research and Innovation Foundation (2018), the Shandong Taishan Scholars Special Fund, the Shandong Provincial Natural Science Foundation, China (ZR2015PE006), the Fundamental Research Funds for the Central Universities (HIT.NSRIF.2017018), and the Scientific Research Foundation of Harbin Institute of Technology at Weihai (HIT(WH)201423).

\section{References}

[1] R. M. Koerner, Designing with Geosynthetics, Prentice-Hall, New Jersey, NJ, USA, 1998.

[2] J. P. Giroud, "Quantification of geosynthetic behavior," Geosynthetics International, vol. 12, no. 1, pp. 2-27, 2005.

[3] J. P. Giroud, "Review of geotextile filter criteria," in Proceedings of the Proceedings of the First Indian Geotextiles Conference, Indian Institute of Technology, Bombay, India, February 1988.

[4] American Society for Testing Materials, ASTM D4751-16, ASTM Test Method for Determining the Apparent Opening Size of a Geotextile, American Society for Testing Materials, Philadelphia, PA, USA, 2016.

[5] European Committee for Standardization, ENISO12956, Geotextiles and Geotextile-Related Products-Determination of the Characteristic Opening Size, European Committee for Standardization, Brussels, Belgium, 1999.

[6] Canadian General Standards Board, CANICGSB-148. 1-10, Fifth Draft, Method 10, Method of Testing Geotextiles,
Filtration Opening Size of Geotextiles, Canadian General Standards Board, Ottawa, Canada, 1991.

[7] Y. Jiao, J. He, P. Y. Zhou, and Z. Q. Cao, "Potential of flocculant-aided soil slurry dewatering in land reclamation: laboratory investigations," Advances Civil Engineering, vol. 2018, Article ID 8040193, 6 pages, 2018.

[8] A. B. Fourie and S. M. Kuchena, "The influence of tensile stresses on the filtration characteristics of geotextiles," Geosynthetics International, vol. 2, no. 2, pp. 455-471, 1995.

[9] A. B. Fourie and P. C. Addis, "The effect of in-plane tensile loads on the retention characteristics of geotextiles," Geotechnical Testing Journal, vol. 20, pp. 211-217, 1997.

[10] C.-S. Wu, Y.-S. Hong, and R.-H. Wang, "The influence of uniaxial tensile strain on the pore size and filtration characteristics of geotextiles," Geotextiles and Geomembranes, vol. 26, no. 3, pp. 250-262, 2008.

[11] M. Edwards and G. Hsuan, "Permittivity of geotextiles with biaxial tensile loads," in Proceedings of the 9th International Conference on Geosynthetics, pp. 1135-1140, Guaruja, Brazil,, May 2010.

[12] A. Rawal, A. Kochhar, and A. Gupta, "Biaxial tensile behavior of spunbonded nonwoven geotextiles," Geotextiles and Geomembranes, vol. 29, no. 6, pp. 596-599, 2011.

[13] A. Rawal and S. K. Agrahari, "Pore size characteristics of nonwoven structures under uniaxial tensile loading," Journal of Materials Science, vol. 46, no. 13, pp. 4487-4493, 2011.

[14] X.-W. Tang, L. Tang, W. She, and B.-S. Gao, "Prediction of pore size characteristics of woven slit-film geotextiles subjected to tensile strains film geotextiles subjected to tensile strains," Geotextiles and Geomembranes, vol. 38, pp. 43-50, 2013.

[15] G. Lombard, A. Rollin, and C. Wolff, "Theoretical and experimental opening sizes of heat-bonded geotextiles," Textile Research Journal, vol. 59, no. 4, pp. 208-217, 1989.

[16] Y. H. Faure, J. P. Gourc, and P. Gendrin, "Structural study of porometry and filtration opening size of geotextiles," in Eosynthetics: Microstructure and Performance, I. D. Peggs, Ed., pp. 102-119, American Society for Testing and Materials, West Conshohocken, PA, USA, 1990.

[17] A. Rawal, P. V. Kameswara Rao, S. Russell, and A. Jeganathan, "Effect of fiber orientation on pore size characteristics of nonwoven structures," Journal of Applied Polymer Science, vol. 118 , no. 5, pp. 2668-2673, 2010.

[18] A. Rawal, A. Priyadarshi, N. Kumar, S. V. Lomov, and I. Verpoest, "Tensile behaviour of nonwoven structures: comparison with experimental results," Journal of Materials Science, vol. 45, no. 24, pp. 6643-6652, 2010.

[19] A. Rawal, "Structural analysis of pore size distribution of nonwovens $\dagger$," Journal of the Textile Institute, vol. 101, no. 4, pp. 350-359, 2010.

[20] A. Rawal and H. Saraswat, "Pore size distribution of hybrid nonwoven geotextiles," Geotextiles and Geomembranes, vol. 29, no. 3, pp. 363-367, 2011.

[21] L. Tang, S. T. Sun, X. W. Tang, and R. X. Zhang, "Analysis of pore size distributions of nonwoven geotextiles subjected to unequal biaxial tensile strains," in Springer Series in Geomechanics and Geoengineering, pp. 842-846, Springer, Berlin, Germany, 2016.

[22] R. A. Silva, R. G. Negri, and D. de Mattos Vidal, "A new image-based technique for measuring pore size distribution of nonwoven geotextiles," Geosynthetics International, vol. 26, no. 3, pp. 261-272, 2019.

[23] A. Rawal, P. V. K. Rao, and V. Kumar, "Deconstructing threedimensional (3D) structure of absorptive glass mat (AGM) 
separator to tailor pore dimensions and amplify electrolyte uptake," Journal of Power Sources, vol. 384, pp. 417-425, 2018.

[24] C. S. Wu and Y. S. Hong, "The influence of tensile strain on the pore size and flow capability of needle-punched nonwoven geotextiles," Geosynthetics International, vol. 23, no. 6, pp. 422-434, 2016.

[25] S. K. Shukla, N. Sivakugan, and S. Mahto, "A simple method for estimating Poisson's ratio of geosynthetics at zero strain," ASTM Geotechnical Testing Journal, vol. 32, pp. 181-185, 2009.

[26] M. E. Kutay, M. Guler, and A. H. Aydilek, "Analysis of factors affecting strain distribution in geosynthetics," Journal of Geotechnical and Geoenvironmental Engineering, vol. 132, no. 1, pp. 1-11, 2006.

[27] P. Verma, M. L. Shofner, A. Lin, K. B. Wagner, and A. C. Griffin, "Inducing out-of-plane auxetic behavior in needle-punched nonwovens," Physica Status Solidi (B), vol. 252, no. 7, pp. 1455-1464, 2015.

[28] R. K. Rowe and B. L. J. Myleville, "Implications of adopting an allowable geosynthetic strain in estimating stability," in Proceedings of the Fourth International Conference on Geotextiles, Geomembranes and Related Products, vol. 1, pp. 131-136, Hague, Netherlands, May 1990.

[29] E. Izadi, T. Decraene, S. De Strijcker, A. Bezuijen, and D. Vinckier, "A laboratory investigation on the impact resistance of a woven geotextile," Geotextiles and Geomembranes, vol. 46, no. 1, pp. 91-100, 2018.

[30] M.-S. Won and Y.-S. Kim, "Internal deformation behavior of geosynthetic-reinforced soil walls," Geotextiles and Geomembranes, vol. 25, no. 1, pp. 10-22, 2007.

[31] P. Schimelfenyg, J. Fowler, and D. Leshchinsky, "Fabric reinforced containment dyke, New Bedford superfund site," in Proceedings of the Fourth International Conference on Geotextiles, Geomembranes and Related Products, vol. 1, pp. 149-154, Hague, Netherlands, May 1990.

[32] ASTM International, ASTM D5199-12. Standard Test Method for Measuring the Nominal Thickness of Geosynthetics, ASTM International, West Conshohocken, PA, USA, 2012.

[33] J. P. Giroud, "Poisson's ratio of unreinforced geomembranes and nonwoven geotextiles subjected to large strains," Geotextiles and Geomembranes, vol. 22, no. 4, pp. 297-305, 2004. 